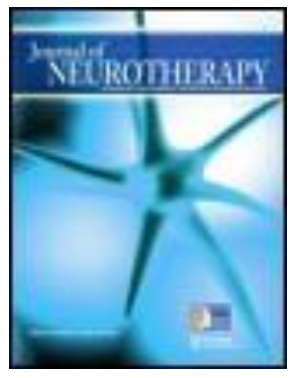

Journal of Neurotherapy: Investigations in Neuromodulation, Neurofeedback and Applied Neuroscience

\title{
Response to Neurofeedback Equipment Study One - Focused Technology F-1000
}

Frank Deits

Published online: 17 Oct 2008.

To cite this article: Frank Deits (2000) Response to Neurofeedback Equipment Study One - Focused Technology F-1000, Journal of Neurotherapy: Investigations in Neuromodulation, Neurofeedback and Applied Neuroscience, 4:1, 71-72, DOI: 10.1300/J184v04n01_08

To link to this article: http://dx.doi.org/10.1300/J184v04n01_08

\section{PLEASE SCROLL DOWN FOR ARTICLE}

(c) International Society for Neurofeedback and Research (ISNR), all rights reserved. This article (the "Article") may be accessed online from ISNR at no charge. The Article may be viewed online, stored in electronic or physical form, or archived for research, teaching, and private study purposes. The Article may be archived in public libraries or university libraries at the direction of said public library or university library. Any other reproduction of the Article for redistribution, sale, resale, loan, sublicensing, systematic supply, or other distribution, including both physical and electronic reproduction for such purposes, is expressly forbidden. Preparing or reproducing derivative works of this article is expressly forbidden. ISNR makes no representation or warranty as to the accuracy or completeness of any content in the Article. From 1995 to 2013 the Journal of Neurotherapy was the official publication of ISNR (Www. Isnr.org); on April 27, 2016 ISNR acquired the journal from Taylor \& Francis Group, LLC. In 2014, ISNR established its official open-access journal NeuroRegulation (ISSN: 2373-0587; www. neuroregulation.org).

\section{THIS OPEN-ACCESS CONTENT MADE POSSIBLE BY THESE GENEROUS SPONSORS}

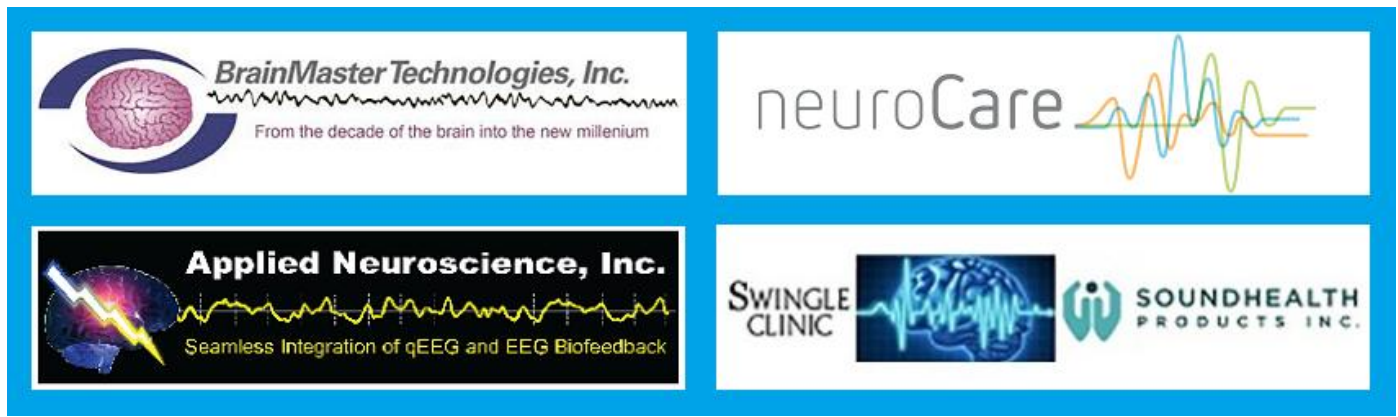




\title{
Response \\ to Neurofeedback Equipment Study One- Focused Technology F-1000
}

\author{
Frank Deits, Design Engineer
}

I appreciate the opportunity to comment on the study by Hamilton and Barnes titled "Neurofeedback Equipment Study 1-Focused Technology F-1000."

The authors correctly state that there are significant differences, both technical and esthetic, between the various equipment available to the clinician. The effects of these differences are not well known. Since the study addressed technical characteristics, I will limit my comments to this area.

The authors' approach to evaluating repeatability in measurement between two F-1000 systems highlights an emerging problem in the physiological feedback field. The disciplines of electronic engineering and physiological science operate in two quite different worlds.

Electronics can be described as a "crisp" science where single measurements are repeatable to a high degree of accuracy. With even the most rudimentary instruments the gain of an amplifier can be measured to an accuracy of $1 \%$. Repeated measurements result in the same values, and the measurements are not dependent on the mental state of the person making the measurements.

Physiological science can be described as a "fuzzy" science where readings are rarely repeatable as single measurements. As an example, blood pressure readings repeated only seconds apart may vary widely. The mental state of both the person taking the measurement and the subject being measured can have large effects on the result. These and

Address correspondence to: Frank Deits, Focused Technology, P.O. Box 367, Ridgecrest, CA 93556 (E-mail: frank@focused-technology.com).

Journal of Neurotherapy, Vol. 4(1) 2000

Copyright (C) 2000 ISNR. All rights reserved. 
other factors lead to the use of statistical methods to provide generalized information based upon multiple samples.

In this study the authors have used fuzzy science where crisp science would be more appropriate. Comparison of the two F-1000 systems could have been better done using established electronic measures. It is a trivial task to verify that multiple systems respond in a consistent manner to identical calibration signals. Filter response can be verified by sweeping a signal across the specified bandwidth. These procedures are performed on each F-1000 as part of its final test before shipment.

Fuzzy science is appropriate in those instances where single measure repeatability is not possible. For example, the effect of filter characteristics such as roll off shape, time delay, ringing, etc., may affect training outcome. EEG amplifier characteristics such as input impedance, common mode rejection, and cable shielding have effects related to clinician procedures. Often these characteristics are tradeoffs that can be chosen within the same instrument and need to be better understood.

Technical Editor, Jay Gunkelman's Note: Though the EEG is a "fuzzy" test of equipment reliability, as Frank Deits properly points out, this methodology is looking for factor loading which would be systematic, a characteristic not imbedded in the "fuzzy" nature of the EEG. Thus, the "fuzzy" nature of the test in no way can be used to dismiss this equipment "factor" evaluation. It is gratifying to see equipment that can pass both evaluations. 